\title{
Impact of Role (Ambiguity and Conflict) on Teaching Assistants' Satisfaction and Intention to Leave: Pakistani HEIs
}

\author{
Goher Fatima $^{1} \&$ Wali ur Rehman ${ }^{2}$ \\ ${ }^{1}$ Department of Management Sciences, Bahria University, Islamabad, Pakistan \\ ${ }^{2}$ Programme Coordinator, Bahria University, Islamabad, Pakistan \\ Correspondence: Wali ur Rehman, Programme Coordinator, Bahria University, Shangrilla Road, Sector E-8, \\ Islamabad, Pakistan. Tel: 92-300-517-1088. E-mail: wrehman88@gmail.com
}

\author{
Received: February 7, 2012 Accepted: July 4, 2012 Online Published: August 16, 2012 \\ doi:10.5539/ijbm.v7n16p56 URL: http://dx.doi.org/10.5539/ijbm.v7n16p56
}

\begin{abstract}
Research assistants play very important role in producing research outputs and in supporting the research in HEIs. The focus of this study, initially, was to enlist the roles assigned to these teaching assistants in various setups (HEIs in this case). However, the impact of role ambiguity and role conflict on satisfaction and their intention to leave was also ascertained. Data was collected from 120 teaching assistants, engaged in various universities in Islamabad and Rawalpindi. The results found that the satisfaction and intention to leave are negatively and positively affected, respectively by these role variables. The universities are recommended to encourage the research assistants by facilitating both in term of monetary and job related factors.
\end{abstract}

Keywords: role ambiguity, higher education institution, intension to leave, teaching assistants

\section{Introduction}

Higher Education institutions plays very important role in developing new skills and polishing the raw skills of human capital. The academicians, responsible for imparting quality education, are facing problems in developing their own skills. The also required to compete in the hyper turbulent environment, where every day there is a huge influx of new knowledge, attributed towards the research works going on globally. They, in some institutions, are facilitated by the universities/institution by provision of assistant in the form of teaching assistants/research assistant/research scholars/ even having various different nomenclatures. These assistants are termed as 'Teaching Assistants' in this study.

Lack of sufficient resources and financial constraints led the universities to utilize their graduate students to teach the students at undergraduate levels. These are due to the larger sizes of the students (due to turbulent increase in the population of the age seeking admissions). According to Gillon and Hoad (2001) higher education institutions utilizes their well-qualified graduates in delivering lectures at undergraduate levels (in their initial semesters or years) in an attempt to cut the costs of engaging professional faculty members.

Chris (2002) defined teaching assistants as those who are graduated or pursuing their post graduate studies and are also being utilized by the university for teaching purposes (usually on payment, but sometime on gratis) besides doing their research work. Major concern of these universities is to bridge the gap, which arises due to the demand (by the students) - supply (of teachers from university) equation. This practice is resulting in two-fold benefits, one for the undergraduate students (for universities) and other for themselves, as in the form of income and teaching experience in their field of study.

These teaching assistants, assigned to these academicians/senior faculty members are selected from various categories, ranging from fresh graduates of the same university, graduates intending to start their career as teachers, students pursuing research dissertation/thesis of their doctoral degrees in different setup, students pursuing doctoral studies under their direct supervisions etc. These assistants may be either paid or working on gratis. There further decision to continue with the organization in a different capacity depends on the environment and their satisfaction level being felt during the assistantship. Apparently they may not surface their reservations regarding the environments (including the behavior with the co-workers, the on the job facilities and pay regarding concerns), but there might be some issues, which could affect their performance.

This very group of the semi-employed workforce has been neglected by the researchers in the field of 
management sciences regarding their satisfaction level, impact on their decision to further continue their career as faculty of the universities, and their intention to leave the university (where they are working as teaching assistant). The study will be very useful for the HEIs in Pakistan to consider the facts regarding the motivation level and the intentions of these assistants regarding their jobs.

The focus of this study, initially, was to enlist the roles assigned to these teaching assistants in various setups (HEIs in this case). Furthermore, the role ambiguity which is a major issue for these temporary semi workers of the universities, as they are, some time, taken for granted and are given extra responsibilities by faculty members, other than that for whom they are appointed/inducted in the university, as these assistants are meant for helping the faculty member(s) in their research and teaching related activities. Such conflicts and ambiguity in their roles are inevitable, in the large academic departments, where every one is involved in research and teaching related activities, side by side. This study considered the teaching assistants involved in the universities operating in the twin-cities of Pakistan (Islamabad and Rawalpindi).

\subsection{Objectives of the Study}

The objectives of the study are to:

1) Enlist the roles and responsibilities assigned to these teaching assistants;

2) Measure their level of satisfaction while performing their duties;

3) Analyze the level of role ambiguity being felt by them;

4) Analyze level of role conflict being felt by them;

5) Evaluate their intention to leave the university; (or measure their desire to start their career in the same organization)

6) Explore any difference between the male and female teaching assistants on their level of satisfaction, role ambiguity, role conflict and their intention to leave the organization.

The next section of the study provided a background regarding the roles of the teaching assistants in the HEIs and their satisfaction level and desire to further continue their job in the same organization. Third section explained the methodology used in the study. Results are provided and interpreted in the fourth section; however, the study is concluded in fifth section. Some positive and optimal recommendations are enlisted in the last section of the paper.

\section{Literature Review}

There is a lot of stress on the satisfaction level of the employees working in the social and service centered organization. The fact being that they have to deal with the stake holders of the organization directly, and are very important for them to be satisfied with their jobs. There are very much stress on the job satisfaction and mental health of the employees working in health based organizations like hospitals, clinic and other medical related institutions. The satisfied worker is an asset both for the organization as well the customer (in the form of student, patient, or any other social sector client).

According to Oberlander (1990), it is very important for the organization to consider the mental health and the satisfaction level of their employees, if they want to provide quality services to their clients. This ascertainment is also supported by Acker (1999. The mental health is very susceptible to the career related factors such as the desire for higher pay, the minimal opportunities for higher education facilities around them (Adams, 2001a). Drolen and Harrison (1990) also suggested that the work load put on their shoulder and lower salaries severely affected the mental health of the new entrants in any organization. According to Colbeck (1998), teachers need teaching assistants to facilitate them in their research and teaching activities, as it is very tough for them to integrate the teaching and research activities.

Acker (1999) argued that the lack of independence for decision making regarding availing opportunities to improve their future results in negative self evaluation, which results in deviation from the conformity between their current professional job and their desired profession. Arches (1997), Drolen and Harrison (1990) and Rosenbaum (1992) also argued the same way and supported the arguments of Acker (1999). Carroll (1980) studied the teaching assistants in contexts of the benefits perceived by them. He explored that several universities provide training programs to the teaching assistants, which attracts the latter to indulge themselves in the TA ships. But, on contrary they are not much benefited from these programs, as perceived, because of the workload and their busy schedule, while discharging their responsibilities.

Chris (2002) highlighted some of the problems faced by the teaching assistants are heavy workload put by their 
seniors, which affects their commitment towards their research work (in case they are also doing post graduation). The other concern is for those who are engaged full time as teaching assistants (regarding payment, which is comparatively less to other teaching staff), which creates dissatisfaction. They are also facing problems of designing and implementation autonomy, as they have to work as instructed by their departments (teaching the way other wants you to teach is difficult, as compared to teaching in your own way). It has been explored and demonstrated by many researches that lack of satisfaction, regardless of the industry, leads to the intention to leave of the workers (who are dissatisfied with their jobs). These factors, which are highlighted by Chris (2002), led conduction of this study, as the impact of role ambiguity and role conflict on the satisfaction of the teaching assistants has been neglected by the researchers, hence this study is an attempt to fill this research gap.

\section{Methodology}

The variables selected in this study are role ambiguity, role conflict, job satisfaction and intention to leave the organization. However, gender and salary is selected as demographic variable to check the difference in the level of the satisfaction and intention to leave being felt by them.

The mathematical representations of the model to be estimated are as follows:

$$
\begin{aligned}
S a t & =\alpha_{1}+\beta_{1}(R A)+\gamma_{1}(R C)+u \\
I L & =\alpha_{2}+\beta_{2}(R A)+\gamma_{2}(R C)+v
\end{aligned}
$$

The equation (1) measures the impact of role ambiguity and role conflict on satisfaction level of the teaching assistant; however, equation (2) measures the impact of role ambiguity and role conflict on the intention of the TA to leave the job. In these equations Sat, RA, RC, IL, u, v, represent satisfaction, role ambiguity, role conflict, intention to leave and the error terms, respectively.

A self administered questionnaire was developed and distributed among the participants, including demographic variables, however to measure the satisfaction of the TA a tool developed by Churchill et al. (1974) was adopted. The 28-item tool measuring each item on the scale of 1-5 (i.e., 1-strongly disagree to 5-strongly agree). Intention to leave of the TAs was measured on a tool developed by Bluedorn (1982) and Johnston et al. (1990). However, Role ambiguity and role conflicts were measured on the tools developed by Johnston et al. (1989); Rizzo et al. (1970).

Sample of 120 teaching assistants indulged in the universities of Rawalpindi and Islamabad (the capital of Pakistan). These teaching assistants were selected on convenience sampling technique, as not all the universities indulged teaching assistants in their universities. There was no choice in the selection of the academic departments and included teaching assistants from all the academic departments of the universities. After collection of the data correlation coefficients and regression analysis were applied to evaluate the results.

\section{Result Interpretations}

The models provided in equations (1) and (2) were estimated using SPSS, and regression analysis was carried out on these two models. The results are provided in the table-1 to 2 for equation (1), however the results of the equation (2) are provided in table-3 to 4 . Graphs provided in the appendices to this article show normality of the data, being one of the assumptions to run regression analysis.

Table 1 represents the model, including the variables included in the model i.e. role ambiguity and role conflict. Role ambiguity and role conflict account for 62 percent variation in the job satisfaction $\left(R^{2}=0.626, F=18.265\right)$. However, role ambiguity and role conflict have significant and negative impact on the job satisfaction $\left(\beta_{1}=-.399\right.$, $p=0.00)$ and $\left(\gamma_{1}=-0.745, p=0.00\right)$, respectively. Both the regression coefficients are significant at 0.01 levels of significance.

Table 1. Variables entered/removed ${ }^{\mathrm{b}}$ (model summary)

\begin{tabular}{lccc}
\hline Model & Variables Entered & $\mathrm{R}$ & $\mathrm{R}^{2}$ \\
\hline 1 & Role Ambiguity, Role Conflict $^{\mathrm{a}}$ & 0.791 & 0.626 \\
\hline
\end{tabular}
a. All requested variables entered.
b. Dependent Variable: Job Satisfaction 
Table 2. Coefficients ${ }^{\mathrm{a}}$

\begin{tabular}{llccccc}
\hline \multirow{2}{*}{ Model } & & \multicolumn{2}{c}{ Un standardized Coefficients } & \multicolumn{2}{c}{ Standardized Coefficients } & \\
\cline { 2 - 5 } & & $\mathrm{B}$ & Std. Error & Beta & $\mathrm{t}$ & Sig. \\
\hline 1 & (Constant) & 3.227 & .191 & & 16.925 & .000 \\
& Role Conflict & -.318 & .079 & -.475 & -4.014 & .000 \\
& Role Ambiguity & -.230 & .068 & -.399 & -3.376 & .001 \\
\hline
\end{tabular}

a. Dependent Variable: Job Satisfaction

Table 3 represents the summary of the model (2), regarding the variables included in the model i.e. role ambiguity and role conflict. In this model role ambiguity and role conflict account for $70 \%$ variation in the intention of the employees to leave the organization $\left(\mathrm{R}^{2}=0.703, \mathrm{~F}=29.070\right)$. However, role ambiguity and role conflict have significant and positive impact on intention to leave $\left(\beta_{2}=.561, \mathrm{p}=0.00\right)$ and $\left(\gamma_{2}=0.622, \mathrm{p}=0.00\right)$, respectively (see table 4 ). Both the regression coefficients are significant at 0.01 levels of significance.

Table 3. Model summary ${ }^{\mathrm{b}}$

\begin{tabular}{cccccc}
\hline Model & R & R Square & Adjusted R Square & F & Durbin-Watson \\
\hline 1 & $.838^{\mathrm{a}}$ & .703 & .698 & 29.070 & 1.494
\end{tabular}

a. Predictors: (Constant), Role Ambiguity, Role Conflict

b. Dependent Variable: Intention Leave

Table 4. Coefficients ${ }^{\mathrm{a}}$

\begin{tabular}{lccccc}
\hline & \multicolumn{2}{c}{ Un standardized Coefficients } & Standardized Coefficients & & \\
Model & $\mathrm{B}$ & Std. Error & Beta & $\mathrm{t}$ & Sig. \\
\hline (Constant) & 1.226 & .267 & & 4.587 & .000 \\
Role Conflict & .603 & .111 & .561 & 5.425 & .000 \\
Role Ambiguity & .020 & .095 & .622 & 6.208 & .000 \\
\hline
\end{tabular}

a. Dependent Variable: Intention Leave

The results of the model validates the a priori regarding the relationship between the role ambiguity and role conflict and the performance and intention of the employees to leave the organization. The graphs provided in the following sections show the normality of the data in both the equations (1) and (2).

\section{Conclusion}

The results have shown that the employees are facing the problems of role ambiguity and role conflict, which also affect their performance through affecting the satisfaction level of the employees. The employees, who are not satisfied with their jobs, may not continue with the organization, unless drastic changes occur therein. These situations go on and resultantly persuading the employees to quit the job, and to search for another. This intention to leave the organization is the indirect result of the role ambiguity and role conflict, as evident from the results of the Tables 3 and 4. It was also observed that these employees are given extra responsibilities, which are deviating from their primary responsibilities, promised to them at the time of their inductions.

The first objective of the study was achieved by including an open ended question in the questionnaire distributed to these respondents. The question was regarding enlisting the responsibilities assigned to the respondents during last six months in the current position of teaching assistant.

On the basis of the feedbacks received from the respondents, a very short list, including the responsibilities very 
frequently assigned to these teaching assistants, was prepared. According to the responses, most frequent responsibilities assigned to the teaching assistants are:
a) Research support to the senior faculty member in their research projects
b) Taking lectures in the absence of the senior faculty member
c) Coordination between the faculty members and the students
d) Students counseling
e) Research Activities performed at departmental level, in order to assess the feedback of students.
f) Assisting the senior faculty member(s) in their academic and research activities
g) Evaluation of the answer sheets of the students
h) Invigilation duties assigned during the examination

\section{Recommendations}

Having stated about the responsibilities assigned to these assistants, it is recommended that they may be assigned such responsibilities, which as a result improve their teaching, research or administrative skills. These skills can help them in their future endeavors. It is further recommended that clear job responsibilities may be defied by the universities, and deviation from these job responsibilities may be discouraged by the management of the universities. Though some universities do have the formalized job responsibilities for the teaching assistants, but their implementation in its letter and spirit has not been observed.

The existence of the law or rule or policy is not the issue or hurdle in the way of improvement in any field, but its implementation according to the spirit of the document/law/policy is the required, which is missing in our society. The management of the universities should also encourage and facilitate these assistant by providing sufficient facilities, which they require in order to discharge their responsibilities. The current study would be beneficial for the universities' management to cope with the problems faced by the teaching assistant, and they can contribute in the body of knowledge, by production of research outputs.

The research implications are for those who want to continue the research in other geographical areas of the country or any other country. Some other variables regarding the environmental factors may also be considered in future research to ascertain the problems faced by the teaching assistants. An open ended questionnaire, which should consider all the problems, related their jobs. The open ended questionnaire, would ascertain the solutions to the problems, which could be put forward for the consideration of the management of the universities, for implementation.

\section{References}

Acker, G. M. (1999). The impact of Clients' mental illness on social workers' job satisfaction and burnout. Health \& Social Work, 24(2), 112-119. http://dx.doi.org/10.1093/hsw/24.2.112

Adams, C. B. (2001a, Fall). The changing face of direct practice. LINKS, George Warren Brown School of Social Work.

Arches, J. L. (1997). Burnout and Social Action. Journal of Progressive Human Services, 8(2), 51-61.

Bluedorn, A. C. (1982). A unified model of turnover from organizations. Human Relations, 135-53. http://dx.doi.org/10.1177/001872678203500204

Carroll, J. G. (1980). Effects of Training Programs for University Teaching Assistants: A Review of Empirical Research. Ohio State University Press. Journal of Higher Education, 51(2), 167-183. http://dx.doi.org/10.2307/1981372

Chris, P. (2002). Neither Fish nor fowl? The perceived benefits and problems of using Graduate Teaching Assistants (GTAs) to teach undergraduate students. Higher Education Review, 35(1), 50-62.

Churchill, G. A., Jr, Ford, N. M., \& Walker, O. C. Jr. (1974). Measuring the job satisfaction of industrial salesmen. Journal of Marketing Research, XI, 254-60. http://dx.doi.org/10.2307/3151140

Colbeck, C. L. (1998). Merging in a seamless blend: How Faculty integrate Teaching and Research. The Journal of Higher Education, 69(6), 647-671. http://dx.doi.org/10.2307/2649212

Drolen, C. S., \& Harrison, W. D. (1990). State Hospital Social Work Staff: Role Conflict and Ambiguity. Administration and Policy in Mental Health, 18(2), 127-129. http://dx.doi.org/10.1007/BF00706979 
Gillon, E., \& Hoad, J. (2001). Postgraduate students as teachers. Lancaster: NPC. Retrieved from http://www.npc.org.uk/page/1003797676

Johnston, M. W., Parasuraman, A., Futrell, C. M., \& Black, W. C. (1990). A longitudinal assessment of the impact of selected organizational influences on salespeople's organizational commitment during early employment. Journal of Marketing Research, XVII, 333-44. http://dx.doi.org/10.2307/3172590

Oberlander, L. B. (1990). Work Satisfaction among community-based mental health service providers: The association between work environment and work satisfaction. Community Mental Health Journal, 26(6), 517-532. http://dx.doi.org/10.1007/BF00752456

Rizzo, J. R., House, R. J., \& Lirtzman, S. I. (1970). Role Conflict and ambiguity in complex organizations. Adminstrative Science Quarterly, 15, 150-163. http://dx.doi.org/10.2307/2391486

Rosenbaum, G. S. (1992). Role conflict and Job satisfaction of Master's level social workers who practice in the acute care hospital settings. DSW, Dissertation, Adelphi University.

\section{Appendix}

Appendix 1. Graph for normality test

Histogram

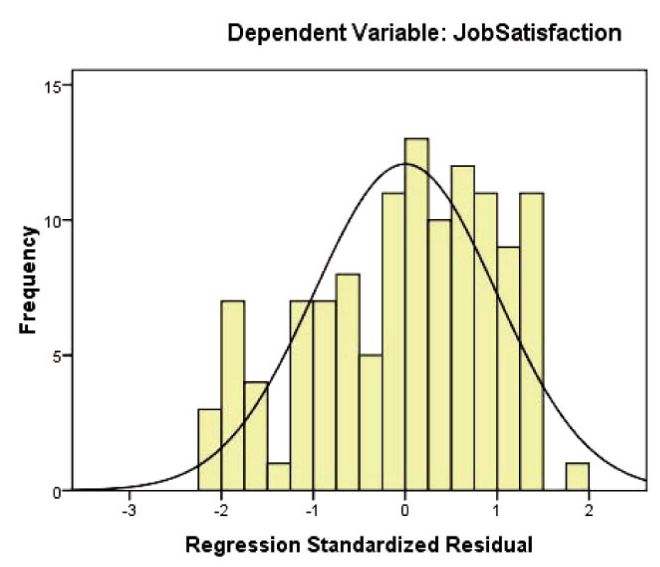

Appendix 2. Graph for normality test
Normal P.P Plot of Regression Standardized Residual

Mean $=6.14 E-16$
Stcd. Dev
$N=120.992$

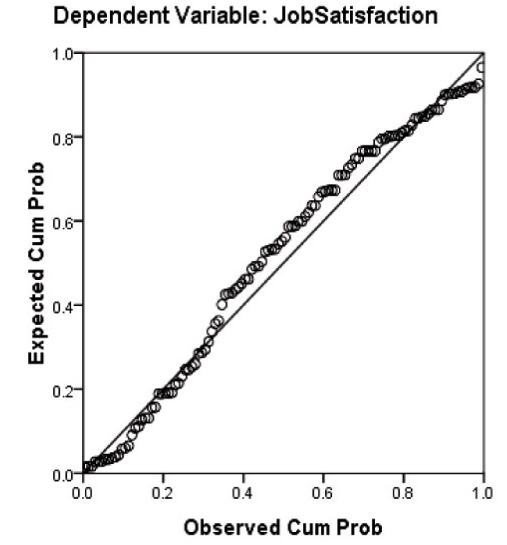

Normal P-P Plot of Regression Standardized Residual

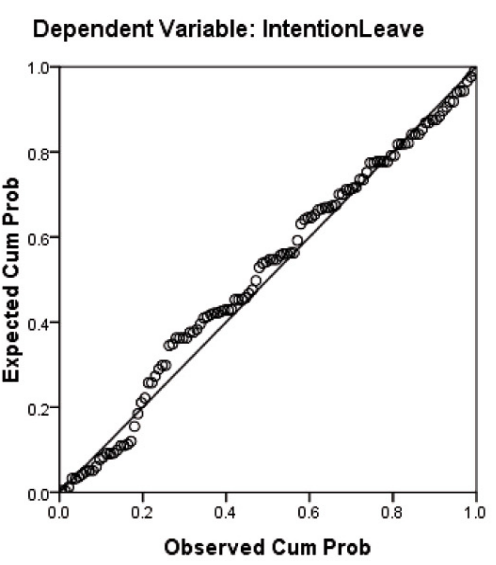

Histogram

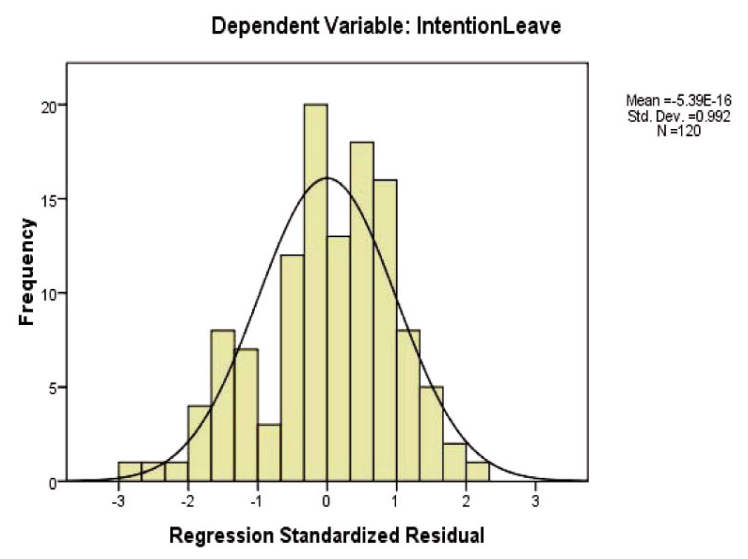

